\title{
Participação Política versus Egotopia: a abordagem constitucional como resposta a concepções ideológicas dos direitos humanos
}

Participación Política versus Egotopía: el enfoque constitucional como respuesta a concepciones ideológicas de los derechos humanos

Political Participation vs. Egotopy: The constitutional approach as a response to ideological conceptions of human rights

\author{
MÁRTIN PERIUS HAEBERLIN ${ }^{1}$ \\ UniRitter, Brasil
}

RECEPCIÓN: 25/09/2017 • ACEPTACIÓN: 23/10/2017

RESUMO: O presente ensaio propõe o entendimento da participação política como um direito constitucional conformado por princípios e regras. A exposição deste argumento, no contexto combativo da experiência política recente em países latino-americanos, incluindo o Brasil, passa por compreender como este direito constitucional separa-se das ideologias, notadamente em razão de elas terem impregnado diversos espaços, dentre os quais o da interpretação dos direitos humanos e fundamentais. Para realizar esse objetivo, primeiro demonstra-se a formação elementar do direito enquanto normatização de interesses individuais, ilustrando sua conformação em princípios e regras. Após, evidencia-se a conexão entre a participação política e as ideologias, a partir da separação entre ideologias em sentido

1. Doutor em Direito (PUCRS/Universidade de Heidelberg, 2014). Mestre em Direito do Estado (PUCRS, 2007). Pós-Doutorado em andamento em Economia (UFRGS, desde 2016), com bolsa da CAPES (Processo n. 23038.004864/2015-63). Pesquisador Visitante do Max-PlanckInstitut fur auslandisches öffentliches Recht und Volkerrecht (2013). Professor de Teoria Geral do Direito e de Direito Administrativo (Laureate/UniRitter). Advogado. email: mphaeberlin@ gmail.com. Link para currículo lattes: http://lattes.cnpq.br/5190995351722855. 
forte e fraco. Ao fim, propõe-se um mecanismo para separar a participação política das concepções ideológicas em favor de uma abordagem constitucional, na qual esta é apresentada desde um mandamento de não "egotopia”, sustentando-se que, enquanto o povo é fundamento da Constituição, deve-se exigir a normatividade que advém de seu texto.

PALAVRAS-CHAVE: Participação política - Egotopia - Direito - Ideologia - Direitos humanos.

RESUMEN: El presente ensayo propone el entendimiento de la participación política como un derecho constitucional conformado por principios y reglas. La exposición de este argumento, en el contexto combativo de la experiencia política reciente en los países latinoamericanos, incluido Brasil, pasa por comprender cómo este derecho constitucional se separa de las ideologías, sobre todo porque estas han impregnado varios espacios, entre ellos el de la interpretación de los derechos humanos y fundamentales. Para lograr este objetivo, se demuestra, en primer lugar, la construcción elemental del derecho como una normalización de los intereses individuales, ilustrando su conformación en principios y reglas. Después, se muestra la conexión entre la participación política y las ideologías, a partir de la separación de las ideologías en un sentido fuerte y débil. Finalmente, se propone un mecanismo para separar la participación política de las concepciones ideológicas en favor de un enfoque constitucional, en el que la participación política se presenta a partir de un mandamiento de no "egotopía", sosteniendo que, mientras el pueblo es fundamento de la Constitución, se debe exigir la normatividad que viene de su texto.

PALABRAS CLAVE: Participación política - Egotopía -Derecho - Ideología Derechos humanos.

ABSTRACT: The present essay proposes that political participation can be understood as a constitutional right composed of principles and rules. To explore this idea in the combative context of recent political experience in Latin American countries, including Brazil, it is necessary to understand how Constitutional Law is to be differentiated from ideologies, particularly because these have impregnated several spaces - including the interpretation of fundamental human rights. In order to achieve this objective, we first show the elementary construction of law as the regulation of individual interests, illustrating how it is composed of principles and 
rules. We then present the connection between political participation and ideologies, starting from the separation of the former from the latter in strong and weak senses. Finally, we propose a mechanism to separate political participation from ideological conceptions in favor of a constitutional approach, in which political participation is presented as being based on non-"egotopy"; we argue that, while the people is the basis of the Constitution, they must demand the regulatory framework that arises from its text.

KEYWORDS: Political participation - Egotopy - Right - Ideology - Human rights

"A ideologia nada mais é, na perspectiva marxista, do que o uso da atividade pensante como recurso de dominio. É um artefato de guerra, com vistas à dominação. Trata-se de uma forma de justificativa teórica do poder, na medida em que traduz, a nivel de subjetividade, verdades e valores a que os homens são sensiveis, justamente porque sua consciência é subjetiva. Contudo, estas verdades e valores, apresentadas como universais, ou seja, como correspondentes aos interesses de todos, correspondem de fato aos interesses de grupos ou de classes sociais restritas".

Antonio Joaquim Severino, Educação, Ideologia e Contra-ideologia

"Is the Constitution simply a mirror in which one sees what one wants to see?"

Laurence Tribe e Michael Dorf, On reading the Constitution

\section{Introdução}

A participação política é emissora e receptora do ideário coletivo. É usual percebêla como um fenômeno ideológico, e não como um direito que medeia a origem e acompanha as Constituições dos Estados Democráticos.

Experiências recentes em países latino-americanos, incluindo o Brasil, levam a pensar que as ideologias avançaram seu posto, olvidando a política para adentrar no sistema jurídico, incluindo a atividade jurisdicional. Vê-se a participação política, nesse contexto, absorvida na arena de debates ideológicos que impregnam 
diversos espaços, dentre os quais o da interpretação dos direitos humanos e fundamentais ${ }^{2}$.

Assumindo como inarredável a premissa de que o direito (pensando em seu conjunto normativo abrangido por princípios e regras) liga-se com as ideologias, entender tal ligação - e realizar seu desligamento - faz-se tão necessário quanto se faz necessário dissociar disposição e posição. Para distinguir, basta que o bom observador, nunca mais do que aquele que quer enxergar, treine seus olhos.

O presente ensaio busca treinar os olhos do bom observador, na medida em que visa a demonstrar a participação política como um direito constitucional. Para realizar esse objetivo, primeiro demonstra-se a formação elementar do direito enquanto normatização de interesses individuais, ilustrando sua conformação em princípios e regras. Após, evidencia-se a conexão entre a participação política e as ideologias, a partir da separação entre ideologias em sentido forte e fraco. Ao fim, propõe-se um mecanismo para separar a participação política das concepções ideológicas em favor de uma abordagem constitucional, na qual esta é apresentada desde um mandamento de não "egotopia".

O desafio de colocar a participação política vis-à-vis da egotopia é encarado, neste ensaio, como um brado de reivindicação do povo - do qual todo poder emana - pelos seus direitos humanos e fundamentais. Não onde o povo é maioria. Nem onde é minoria. Mas onde ele é fundamento da Constituição ${ }^{4}$ e, portanto, exige a normatividade que advém de seu texto.

\section{A participação política como direito constitucional entre princípios e regras}

Os direitos nascem dos interesses e de sua proteção. Considerando os sujeitos como pessoas concretas, não como entes abstratos, não é difícil assentar que a questão do interesse -mais propriamente, da pluralidade dos interesses- é pressuposta aos problemas relacionados à participação política. Pensar a participação política das mais diversas comunidades é pensar em respostas jurídicas para a multiplicidade de interesses pessoais.

2. O argumento elaborado no presente texto prescindirá de uma distinção entre direitos humanos e fundamentais, uma vez que o fenômeno aqui assinalado ocorre para ambos.

3. Cf. Haeberlin (2017), p. 285-93, base na qual a ideia central deste texto é desenvolvida.

4. ISENSEE (1995). 
A busca por respostas jurídicas a esses problemas (em contraposição às respostas jogadas aos ventos das ideologias)passa por reconhecer a carga eficacial dos princípios e das regras -de resto já consolidada no direito contemporâneo-, mas também por inserir a participação política nesse espaço de princípios e regras. Isso é: pensar a participação política em termos constitucionais. Necessário, assim, falar de princípios e regras desde os interesses, que formam os princípios e as regras.

\subsection{Pessoa e Sociedade: os interesses e sua proteção pelo direito}

Os "[i]nteresses são constitutivos para os humanos como pessoa" . É a partir de seus interesses que os indivíduos colocam-se em relação com o meio.

Assumem os interesses um papel de extrema relevância para o direito. Tome-se o exemplo do direito positivo. Para concordar ou discordar de Michel de Montaigne, quando diz que "[a]s leis mantêm o seu crédito não porque são justas, mas porque são leis" ", somos obrigados a perguntar: na ausência de um fundamento transcendente, o que faz das leis, leis? A pergunta leva a uma conclusão: os interesses. Eles são anteriores e formam a lei positiva.

Com efeito, o legislador elabora o direito positivo deflagrando o seu interesse e o interesse daqueles que representa. Originam-se as leis de posições interessadas, às vezes no conflito de cidadãos em defesa do que é seu. Razão parece assistira Jhering: o direito não é um conjunto de operações linguísticas, mas uma luta do sujeito “interessado" (Berechtigten) ${ }^{7}$ em duas dimensões: uma de caráter pessoal, no dever do interessado em relação a ele mesmo;outra de caráter social, no dever do interessado em relação à sociedade.

$\mathrm{Na}$ dimensão pessoal, deve-se considerar que "[o] único motivo que há para me guiar na alegação jurídica do patrimônio é o mesmo que determina a sua aquisição e o seu uso: o meu interesse - um processo sobre o Meu e o Teu é uma questão puramente de interesse" ${ }^{\text {. }}$. Na dimensão social, o interesse e o dever são ampliados, de modo que

[t]odos têm o ofício e a obrigação de esmagar a cabeça da Hidra do arbítrio e da ilegalidade onde quer que ela ouse aparecer. Todo aquele que aproveita
5. GRIMM (1991), p. 176.
6. Montaigne (1595) s/p.
7. JHERING (1992) p. 64-70.
8. JHERING (1992) p. 96. 
as bênçãos do direito deve também contribuir, fazendo a sua parte, para a manutenção do poder e do prestígio da lei. Em síntese: todo mundo é um lutador nato pelo direito no interesse da sociedade?

Em ambas as dimensões, o direito positivo passa a existir na forma de princípios ou regras, quer de modo institucionalizado (com interesses manifestados via mecanismos diretos ou de representação), quer de modo revolucionário (com rompimentos institucionais). E segue existindo como manifestação de interesses quando estes desembarcam no momento da geração dos efeitos da lei, em caráter de execução administrativa ou de interpretação jurisdicional. A finalidade da lei insculpida pelo interesse que a criou, afinal, também possui uma função democrática de retificar execuções e interpretações equivocadas por irem contra o escopo da lei, pois " $[o]$ papel da judicatura não é guiar-se pelo sentimentalismo; e sim, manter o equilíbrio dos interesses, e dentre estes distinguir os legítimos dos ilegítimos" ${ }^{10}$.

As tensões políticas geradoras de lei são, sim, criadoras de direitos. Jhering, após Der Kampf um's Recht, identificou o interesse com uma pretensão, sustentando que a vontade de um sujeito corresponde sempre a um fim almejado. Desse modo, devemos buscar não o processo interno da criação da vontade, mas a sua representação externa, eis que o que move a vontade não é a vontade em si, mas o fim que ela almeja alcançar. Em suas palavras:

Agora que nos voltamos à vontade humana, limitamo-nos no presente capítulo apenas à tarefa de provar a lei da finalidade, ou a seguinte sentença: não há vontade sem fim. Expressando de modo negativo, isso significa que: a vontade, o processo interno de formação da vontade, não obedece à lei da causalidade. Seu móbil fundamental não é a origem, mas o fim. No entanto, a efetivação da vontade, seu aparecimento no mundo sensível obedece à lei da causalidade. Esse estágio da vontade nós podemos chamar de a externalidade do interno ${ }^{11}$.

A teoria do interesse implica pensar o direito como uma força-tarefa em seu dever de ligar o sujeito aos fins que busca alcançar, de modo que uma função do direito, senão a sua grande função, é a de proporcionar o reto exercício da

\footnotetext{
9. JHERING (1992) p. 111.

10. Maximiliano (2005), p. 69.

11. JHERING (1877), p. 11.
} 
causalidade, negando-se tanto quanto possível abandonar o sujeito ao acaso de uma vontade não-efetivada. Em outras palavras, o direito subjetivo assenta um certo compromisso em ultimar a vontade do agente e, por isso, está ele antes no interesse (o fim, o bem) que na própria vontade (a origem, a causa). "Realmente, é sempre o conceito de interesse protegido que constitui a essência do direito subjetivo" ${ }^{12}$. A efetivação do interesse de cada sujeito é, portanto, o momento máximo do direito subjetivo, onde se pode verificar uma realização ótima da lei da causalidade. Ela está ali onde a causa (vontade) encontra o seu fim (interesse).

Entende-se, nessa ordem de coisas, que o interesse pode ser caracterizado como "o nexo tendente a adir a um sujeito o bem que ele estima" ${ }^{13}$. Como as sociedades caracterizam-se pela pluralidade de pessoas, não é difícil compreender que interesses distintos -sujeitos buscando bens variados- podem se excluir mutuamente. Ocorre que, nem no mundo ideal (como o almejado pelo direito positivo), nem no mundo sensível (onde as coisas acontecem), a efetivação de um direito subjetivo de uma pessoa ou de um grupo de pessoas deve produzir uma desvantagem a outra pessoa ou grupo de pessoas.

Favorecer uma expansão, qualitativa e quantitativa, do sistema jurídico contrariando, pois, a teoria tradicional quando sustenta que o direito de alguém corresponde milimetricamente ao dever de outro, numa equação de soma zero ${ }^{14}-$, é uma tarefa de um direito contemporâneo inserido nos problemas da pluralidade. E da participação política.

\subsection{Princípios e regras: lares textuais da participação política}

Embora a palavra arché ( ) tenha origem grega, sua representação costuma ser judaico-cristã, sintetizada em Gênesis 1:1: "No início Deus criou o céu e a terra". Arché, desde sua constituição semântica, guarda este significado de "início das coisas" ou "causa". Vê-se no vocábulo uma ideia de fundação universal de todo e qualquer sistema.

Contudo, a noção de arché não está apenas no início do sistema. Além de o originar, está presente em seu movimento, no "ser-para-a-morte" (Sein-zum-Tode),

12. ZANOBINI (1950), p. 149.

13. Haeberlin (2017), p. 106.

14. Pontes de Miranda (1972), p. 24. 
como criara Martin Heidegger ${ }^{15}$. Um sistema que se constitui inevitavelmente se reconstitui, fazendo seu sentido fundante (do passado) ecoar no presente. $\mathrm{O}$ fim almejado da criação caminha em vigília com os atos ocorrentes na vida do sistema, inclusive pela lembrança aristotélico-tomista de que toda ação visa a um fim. Apreendendo esse significado, ensina Fernando Rey Puente: "O fim aspirado pelo homem é o princípio da sua ação. Eis aqui enunciado mais uma vez, ainda que apenas implicitamente, o caráter circular da teleologia aristotélica. [...] O bem a que aspiramos é o que nos incita a agir" ${ }^{16}$.

Assim, comunga a arché o "início das coisas" e o desenvolvimento das coisas iniciadas. Se, de um lado, ela representa a criação, de outro representa a poeira cósmica que não esvoaça dissipando-se; ao contrário, permite e é requisito do gravitar.

O direito, enquanto sistema, possui uma arché, um conjunto de princípios sob os quais ele é fundado. Não à toa chamamos essa arché de "princípios jurídicos”. Eles são princípios porque estão no início constitutivo do sistema. Mas sua função de princípio não se esvazia na gênesis. Ganha superior mister no seguir-viagem, impulsionando o sistema jurídico, como força modal, avante. Os princípios “[...] voltam-se para o futuro, mas, quando originários e intangíveis, tendem à vinculação em todos os tempos" ${ }^{17}$.

É somente assim, neste tema circunstanciado por contrapontos intermináveis, como na fuga infinda de $\mathrm{Bach}^{18}$, que se pode reconhecer os princípios jurídicos como sendo a arché do sistema jurídico. A definição de princípios como arché é pertinente para percebermos que os princípios, no bojo das complexas, dinâmicas, plurais (e por que não caóticas, se "o direito guarda fractalidade" ? ${ }^{19}$ ) relações sociais, são elemento constitutivo e ultima ratio do ordenamento jurídico.

A noção de princípios como "arché do sistema jurídico" afasta, e daí a sua importância prática, uma outra noção, outrora incutida no direito, segundo a qual os princípios possuíam um caráter subsidiário, onde eram espécie de salvaguarda do “dogma da completude" ${ }^{20}$. Diferentemente, na noção aqui defendida viram-se os valores supra-positivos outorgarem aos princípios um mandato: os princípios

15. HeIdegGer (1951) passim.

16. Puente (2003), p. 5.

17. Freitas (2004), p. 228.

18. Cf. CANDÉ (2001), p. 534.

19. Aronne (2006), p. 34.

20. Cf. Guastini (2005), p. 178-182. 
foram escolhidos para representar os valores dentro do sistema jurídico, via Carta Magna, a partir do fenômeno de sua positivação.

Com isso, entende-se que "[...] um princípio, seja ele expresso numa formulação legislativa ou, ao contrário, implícito ou latente num ordenamento, constitui norma, aplicável como regra-acrescenta Crisafulli- de determinados comportamentos públicos ou privados" 21 . Surge, daí, um acordo semântico relativamente consensual na atualidade sobre como entender princípios e regras: "Os princípios são normas e as normas compreendem as regras e os princípios" 22 .

Porém, à clareza da visualização teórica que compreende as normas como gênero das espécies princípios e regras, segue a dificuldade in concreto da, por vezes incômoda, diferenciação entre princípios e regras.

Isto porque, em alguns casos, somos levados intuitivamente a perceber quando estamos diante de uma ou outra espécie normativa. O mandamento da "equal protection clause" presente em diversas Constituições democráticas, por exemplo, percebe-se facilmente como um princípio; já a definição do número de parlamentares no Congresso, é exemplo claro de uma regra. Todavia, é compreensível defrontarmos com algumas normas - como aquela da inviolabilidade dos parlamentares sobre seus votos e opiniões - e crivarmos certa dúvida sobre a espécie de norma sobre a qual estamos a tratar, se um princípio ou uma regra.

Essa dificuldade pode ser encontrada em relação ao direito à participação política. Qual o lar textual desse direito no contexto constitucional brasileiro? É ele dimensionado por um princípio ou por uma regra?

A fim de responder essa questão, parece imperativo partir de um lugar comum para, tão logo, dele afastar-se. O lugar comum é o modelo de regras sugerido por Ronald Dworkin, onde se tem um critério distintivo ontológico e um critério lógico entre essas espécies normativas. Em relação ao ontológico, aprende-se que os princípios possuem um grau maior de abstração que as regras, além de uma abrangência "moral”, sendo possível conceituá-los como "[...] requerimento de justiça (justice) ou imparcialidade (fairness) ou de alguma outra dimensão da moralidade" ${ }^{23}$. Em relação ao lógico, verifica-se que a aplicação de ambos seria distinta. As regras aplicando-se em método disjuntivo de tudo-ou-nada (all-or-nothing) e os princípios

21. BONAVIDES (2004), p. 273.

22. BONAVIDES (2004), p. 271.

23. DWORKIN (1999), p. 22. 
por uma dimensão de peso ou importância (weight or importance $)^{24},{ }^{25}$.

$\mathrm{O}$ afastamento do lugar comum, por outro lado, sugere a necessidade de tratar o direito à participação política a partir de um modelo integrado de princípios e regras. Do ponto de vista teórico, este modelo é fundamentado na ideia de $A n$ Integrated View on Rules and Principles, em que três autores, com originalidade em seu tempo,sustentavam já a incompatibilidade da caracterização das regras segundo a operatividade do "tudo-ou-nada". Segundo eles,

[...] regras e princípios têm a mesma estrutura lógica mas diferente comportamento na justificação. Nesta visão, deve-se considerar que tanto regras como princípios consistem em uma condição e uma conclusão. As diferenças observadas entre regras e princípios são, em nossa visão, o resultado de diferentes tipos de relações que eles possuem com outras regras e princípios. $\mathrm{Na}$ visão integrada, regras típicas e princípios típicos são os extremos de um espectro ${ }^{26}$.

Com efeito, princípios e regras -ainda que tenham abrangências distintaspossuem uma mesma estrutura, sintetizável na fórmula "Se fato, deve ser consequência”, a qual, ubíqua na normatividade, não difere a feição positiva dos princípios e das regras, ainda que perceba, na aplicação, maior complexidade aos princípios.

A lembrança é oportuna porquanto, ao tratarmos da participação política, vemos que o seu lar textual na Constituição brasileira - e assim ocorre em diversos ambientes constitucionais - não recebe um tratamento singularizado em preceito único. Ao revés, trata-se de um satélite que compreende desde dispositivos do preâmbulo constitucional (v.g.: "livre exercícios dos direitos”, "harmonia social”), passando por disposições mais abstratas (v.g.: "princípio democrático”, "cidadania”, "pluralismo político", "liberdade de manifestação do pensamento") e menos abstratas (v.g.: "reunião pacífica em locais públicos independentemente de autorização, com comunicação prévia", "sufrágio universal, com voto direto", "participação mediante plebiscito, referendo e iniciativa popular”). Veem-se, aqui e ali, interesses que, na "luta pelo direito", foram positivados.

Ao se tratar da participação política como direito, deve-se absorver essa

24. Dworkin (1999), p. 26.

25. Vários autores elaboraram distinções a partir da formulação de Ronald Dworkin. Cf., por exemplo, Alexy (1994); Canaris (1989); Ávila (2005) p. 63-70; Freitas (2004) p. 228-30.

26. Verheij et al. (1998), p. 3. 
estrutura constitucional que compreende uma atmosfera complexa em que os interesses plurais traduzem-se na necessidade de concordância de princípios e regras, tornando a tarefa do intérprete de um peso que acompanha, em direta proporção, os interesses colididos.

Há, parece-nos, dois modos de lidar com tal tarefa. Um é a negando, ou negando o seu peso(o que, na prática, se revela idêntico). Faz-se isso quando a decisão jurídica dá lugar à concepção ideológica, adotando-se uma postura a priori de mimetização do caso para o favorecimento de um ideário. Outro modo é conferir à decisão jurídica sua densidade, sopesando a posteriori os "atratores" 27 envolvidos (valores, princípios, regras, argumentos, fatos, utilidade) nos interesses colidentes. Naquele caso, normalmente tem-se uma utopia produzindo o que podemos chamar de “egotopia”. Neste caso, e apenas nele, a egotopia cede à pluralidade exigida pela participação política.

\section{A participação política e as ideologias}

Não obstante a estrutura constitucional da participação política exija seu tratamento a partir de princípios e regras, é usual entendê-la ideologicamente.

Evidentemente, tendo o Brasil passado, nos últimos cinco anos, por diversas manifestações populares (como os protestos de junho de 2013) e por um processo de impeachment de uma presidente da República, tornou-se o país um laboratório interessante para pensar a participação política. Também a América Latina, especialmente com o fluxo cambiante de ideologias que se veem assumir o poder nos países que a integram - por vezes com radicalização de direita e esquerda-, tem sido um laboratório interessante.

Há de se entender, pois, que a participação política não é adstrita às respostas jurídicas, mas possui efeitos ideológicos, os quais devem ser também e igualmente entendidos. Procura-se, neste tópico, realizar essas aproximações.

\subsection{Ideologias como práxis: conteúdo e características das ideologias}

A palavra práxis (๘ ), assim como a analisada "arché", possui origem grega, significando uma atividade humana na qual a atividade em si e o seu produto são indissociáveis. A palavra, contudo, nos é tradicionalmente lembrada desde

27. Aronne (2006). 
a concepção de uma "filosofia da práxis" elaborada por Karl Marx e Friedrich Engels $^{28} \mathrm{e}$, posteriormente, Antonio Gramsci ${ }^{29}$, sobretudo nos seus estudos referenciais acerca da ideologia ${ }^{30}$. E aqui já aparece a razão de se explicar as ideologias como práxis. As ideologias usam compreensões teóricas do tecido social para as impregnar nesse mesmo tecido. Trata-se, pois, de um comportamento que se afasta do pensar na busca da realização material do pensamento, envolvendo e transformando seu objeto.

Esse sentido de práxis marca a dicotomia interpretar/transformar assinalada por Marx e Engels na famosa XI Tese sobre Feuerbach, ao afirmarem que os filósofos até então apenas interpretaram o mundo, quando a questão que se impunha era transformar o mundo ${ }^{31}$.

A “filosofia da práxis” era uma crítica da ideologia - da ideologia burguesa ou, se se quiser, da ideologia do status quo. Porém, o movimento de crítica às ideologias, exatamente porque ideologia é práxis, tende a produzir ideologias contrárias. Identificada a ideologia posta em xeque, opõe-se a ela uma outra. No exemplo, a "ideologia marxista", cujo escopo teórico era a apresentação da história como a história da luta de classes ${ }^{32}$ e o plano de realização material era a revolução da classe oprimida e alienada (o proletariado) ${ }^{33}$.

Não obstante a referência à ideologia como práxis tenha nos remetido diretamente a Marx e Engels, há um manancial teórico, anterior e posterior a esse referencial canônico sobre o tema, que se mostra conveniente resgatar, ainda que em apertada síntese histórica ${ }^{34}$.

Assim o fazendo, cumpre ressaltar que, historicamente, o termo "ideologia" foi cunhado por Destutt de Tracy, em livro publicado em 1801 intitulado Eléments d'Idéologie, onde assumia significado distinto daquele que hoje utilizamos. Tratavase da pretensão de elaborar uma genealogia das ideias, construída a partir de uma

28. Marx y Engels (2002).

29. Gramsci (1975).

30. Para uma comparação dessas duas referências, vide: FineluI (2001), p. 99-121.

31. ENGELS (s/d).

32. Marx y Engels (2002), p. 23.

33. Poder-se-ia, na distinção que faz Karl Mannheim, sustentar que o marxismo seria melhor designado como uma utopia, onde a força de transformação social é uma nota característica. Cf. Mannheim (1976).

34. Essa pesquisa histórica foi aportada desde quatro referências: ARENDT (1962); POPPER (1987); Chauí (1984); e Severino (1986). 
teoria das faculdades sensíveis aptas a relacionar o corpo humano e o meio ambiente. Na esteira da racionalidade moderna, a ideologia de De Tracy (seguida por Cabanis, De Gérando e Volney), de um lado, apresentava uma crítica às concepções metafísicas do conhecimento, especialmente as teológicas, e, de outro, ambientava uma nova pedagogia e uma nova moral inadequados ao Ancien Régime. Tal ideário os uniu com Napoleão Bonaparte no golpe de 18 Brumário, união que durou pouco, eis que se desapontaram com as características do governo napoleônico, assemelhadas àquela que combatiam. Do rompimento, mais precisamente de um discurso de Napoleão contra os "ideólogos", surgiu o sentido pejorativo do termo.

Posteriormente, Auguste Comte resgatou o termo em seu Cours de Philosophie Positive (cujo primeiro dos seis volumes publicou em 1830), apresentando, ao lado desse sentido de formação e genealogia das ideias, criado por De Tracy, o sentido de um conjunto de ideias de uma época, as quais, originadas nas opiniões correntes, são organizadas, sistematizadas e corrigidas pelos pensadores, cuja responsabilidade é a transformação de seu espírito teológico ou metafísico em um espírito científico ou positivo.

O termo seria retomado em seu sentido pejorativo em Les règles de la méthode sociologique (1895), por Émile Durkheim. A sociologia, segundo o autor, no propósito de estudar a sociedade e sanar suas patologias, deveria ser operada por um método cujas regras permitiriam ao sociólogo, de modo neutro e objetivo, separar o sujeito do conhecimento (sociólogo) do objeto do conhecimento (fatos sociais) do mesmo modo que o cientista investiga os fenômenos da natureza. Durkheim denomina ideologia, e daí seu cunho pejorativo, todo conhecimento da sociedade que não respeite as regras do método sociológico.

A questão da ideologia repercutiu, posteriormente: na chamada "sociologia do conhecimento" de Karl Mannheim e Max Weber ${ }^{35}$; na perspectiva hermenêutica de Paul Ricoeur; nas “vertentes marxistas” de György Lukács, Nicos Poulantzas e Maurice Godelier; e aportou na "teoria crítica” da Escola de Frankfurt, com as obras de Herbert Marcuse, Walter Benjamin, Theodor Adorno, Max Horkheimer e Jürgen Habermas, os quais forneceram uma reflexão sobre uma "ideologia tecnocrática", uma forma de ideologia que vê na ciência -com suas vestes de um conhecimento racional, objetivo, neutro e voltado para a operacionalidade- um instrumento totalitário de dominação e manipulação do homem e da natureza. O poder da técnica, assim, colocar-se-ia acima inclusive do poder político, esfacelando-o.

35. Além de Max Scheller, Theodor Geiger, Gérard Degré, Pitirim Sorokin, Talcott Parsons, Pareto, Gurvitch e Stark. Cf. SEverino (1986), p. 14. 
Historiadas as concepções de ideologia, mostra-se oportuno citar a síntese produzida por Antonio Severino sobre os elementos significativos fundamentais da ideologia, os quais expressa em cinco "processos": o de relação da consciência à realidade social; o epistemológico e axiológico; o de dissimulação e ocultamento; o que envolve o jogo das relações de poder; e o inconsciente e coletivo ${ }^{36}$.

Todos esses processos, sem exceção, puderam ser testemunhados nas relações sociais do último século, o que levou à imperativa conclusão de José Osvaldo de Meira Penna:

[...] o século XX é um século eminentemente político e ideológico. Assemelhase aos séculos XVI e XVII, no sentido em que é assolado por guerras de religião, salvo que as religiões que se enfrentam são 'religiões civis', 'religiões políticas' e religiões ersatz. São, em outras palavras, ideologias ${ }^{37}$.

A mais importante e embrionária ideologia testemunhada no referido século, ao menos nesse sentido de "religião civil”, sem dúvida, foi o marxismo. Marx morreu, assim como, desde a queda do Muro de Berlim, declarou-se a morte -tal vez precipitadamente e sem verificação da certidão de óbito- do comunismo. ${ }^{38} \mathrm{Se}$ nossa exposição começa com Marx, mostra-se natural a pergunta sobre se o século XXI, dos quais se viveram os primeiros meados, é ou será ele também prenhe das revoluções sob signos ideológicos.

A resposta, ainda no plano hipotético, parece indicar o paradoxo falsídico de um "não" seguido de um "e sim". Resolve-se o paradoxo dividindo-se a resposta quanto à forma, onde a resposta parece o "não", e quanto ao conteúdo, onde a resposta é então complementada.

Quanto à forma, isso é, o modo revolucionário como surgiram e se debelaram as ideologias e contra-ideologias, parece que o futuro próximo das sociedades tende a refrear o seu nascedouro ${ }^{39}$. Isso porque, do ponto de vista da forma, as ideologias: quando inicialmente revolucionárias, tendem a convalescer contra mandamentos onipresentes das Constituições contemporâneas e contra os mecanismos de coerção

36. SEVERINo (1986), p. 29-31.

37. Meira Penna (1994), p. 21.

38. Cf. Fukuyama (1992).

39 O argumento aqui expostotem morada nos Estados Democráticos de Direito. Não se descuida, porém, dos movimentos revolucionários que ocorreram recentemente, estão ocorrendo e poderão vir a ocorrer, especialmente no oriente (como no Marrocos, Egito, Tunísia, Líbia, Argélia, dentre outros) e no ocidente, em especial na América Latina (como, atualmente, na Venezuela). 
do Direito Internacional erigidos exatamente contra o que se fez no passado em nome delas; quando inicialmente não-revolucionárias, tendem a se ver abrigadas no pluralismo assente nessas mesmas Constituições e, portanto, sem propensão à revolução.

Já quanto ao conteúdo, o mesmo não se pode dizer. Isso porque a revolução não é a substância da ideologia. Sua substância são as imperfeições ínsitas à existência do homem na pluralidade social. Lapidar, no ponto, a lição de Paul Ricouer: "a ideologia é um fenômeno insuperável da existência social, na medida em que a realidade social sempre possui uma constituição simbólica e comporta uma interpretação, em imagens e representações, do próprio vinculo social" 40.

As ideologias, na esteira da existência do próprio homem, seguirão existindo. Para existir, assim como os pássaros que buscam revoada após perder seu ninho em tempestade, tendem a fabricar ninho novo em que possam pousar. Do ponto de vista jurídico, o qual nos interessa nesse ensaio, parecem inarredáveis dois lugares para o pouso. Um benfazejo, que é o espaço dentro da ordem constitucional, a qual reserva um ninho a toda e cada uma das ideologias. Outro nocivo, que é o espaço à margem da ordem constitucional, na qual as ideologias agem como os chupins, que deixam seus ovos em ninhos alheios e forçam outras aves, sub-repticiamente, a os chocar e criar seus filhotes. ${ }^{41}$

\subsection{Distinção entre ideologia "fraca" (intra constitucional) e ideologia "forte" (praeter constitucional)}

São conhecidas -clássicas até- as abordagens que ligam direito e ideologia ${ }^{42}$. Partimos desta premissa: eles são, de fato, inseparáveis. Colocam-se como objeto de nossa análise, não obstante, os seguintes problemas: (i) com que tipo de ideologia o direito liga-se (ou deve ser ligado) e como deve se operar essa ligação?; (ii) como o direito e a ideologia separam-se (ou devem ser separados)? ${ }^{43}$.

Para responder à primeira questão, lembramos que se costumam diferenciar

40 Ricoeur (1977), p. 75.

41 Sobre o "comportamento mafioso" desses pássaros, no sentido de obrigar as suas vítimas (outras aves) a chocar os ovos e criar os seus filhotes sob a ameaça de destruição dos ovos "legítimos", vide: Hoover y Robinson (2007).

42 Sobre o tema, vide: Colin (1979); Hunt (1985); Halpin (2006); e Lumia (2003), na literatura estrangeira; Wolkmer (2000); Portanova (2003); e Coelho (2002), na literatura brasileira.

43. Cuidaremos da primeira pergunta neste tópico e da segunda no tópico seguinte. 
dois tipos de ideologias, as quais, embora sejam referidas em díades de nomes os mais diversos (como "fraca", "neutra" ou "total", de um lado, e como "forte", "crítica" ou "parcial", de outro), em suas respectivas apresentações, não variam muito em conteúdo. Adotaremos aqui os termos "forte" e "fraco", por acreditar mais representativos que os demais ${ }^{44}$.

A ideologia fraca é aquela apreendida pela sociologia do conhecimento: a compreensão de diferentes correntes de pensamento quando abstraídas as intenções morais e políticas no sentido de ação. Embora não parta dessa divisão, parece-nos correto dizer que esse é o tipo de ideologia que Marilena Chauí conceitua - depois de salientar que ideologias não são subjetividades, pré-conceitos ou ideias falsas como "uma certa maneira de produção das ideias pela sociedade, ou melhor, por formas históricas determinadas das relações sociais" 45 .

Já a ideologia forte é a representação ilusória tecida na sociedade e que está impregnada por interesses escusos visando à dominação. Age, pois, em prol de interesses particulares alienada do bem do comum. Tal sentido é representado pela concepção marxista de ideologia, resumida na frase epigrafada, onde se expõe a ideologia como "o uso da atividade pensante como recurso de dominio" ${ }^{46}$. E também representado pela ideologia neoliberal, assim denunciada por Paulo Freire: "A capacidade de penumbrar a realidade, de nos 'miopizar', de nos ensurdecer que tem a ideologia faz, por exemplo, a muitos de nós, aceitar docilmente o discurso cinicamente fatalista neoliberal que proclama ser o desemprego no mundo uma desgraça do fim de século" ${ }^{47}$. Esse tipo de ideologia é uma marca deletéria emprenhada em diversos debates acadêmicos, conforme testemunha Ernildo Stein: "com Gadamer, me libertei da camisa-de-força do debate ideológico que envenenou muitas cabeças no Brasil" 48 .

Divisados os tipos de ideologias, é possível notar, em resposta à pergunta que nos pusemos a responder, que o direito liga-se, num primeiro momento (o momento da política constitucional), a ambas. Todavia, em momento posterior, endossa apenas a ideologia em sentido fraco, do modo como expressa na Constituição.

44. Essa distinção pode ser lida em: ARNOUD (1999), p. 380.

45. Chauí (1984), p. 31.

46. SEVERINO (1986), p. 9.

47. Freire (2002) ,p. 142.

48 Entrevista transcrita. Disponível em: <http://www.ajaxme.com/gratis/novidades-web/ ernildo-stein-uma-ponte-entre-a-consciencia-e-o-mundo>. Acesso: 27 de jun. 2017. 
Com efeito, enquanto o direito é ainda um estágio da política (estamos pensando, portanto, desde uma concepção positivista, em que direito é “ato de vontade" ${ }^{49}$ ), deve lidar ele com a formação de um consenso em torno do qual se funda a ordem constitucional, onde as ideologias em sentido fraco e, inevitavelmente, em sentido forte estão presentes. Operado o consenso, ele se apresentará como presença da diferença ${ }^{50}$. Algo do tudo é incorporado no texto constitucional. Este, no preenchido e no vazio de suas palavras -como no silêncio de uma ária às vezes integra a melodia-, conjuga os elementos políticos subjacentes à democracia. Noutras palavras: parcializa-se a "vontade de poder" (Wille zur Macht ${ }^{51}$ ) dos singulares para as desdobrar na parte da pluralidade que admite coerção.

É por conservar a diferença que o texto constitucional obriga. A parcialização da Constituição faz do seu texto, portanto, um "produto de compromissos substantivos" 52 , o qual "reflete o esforço de sua geração fundante em eliminar o legado monárquico, baseado na 'natureza' e na 'autoridade', e o substituir por uma república das razões" ${ }^{33}$.

Realizado o consenso, nenhuma ideologia, forte ou fraca, pode usar o próprio compromisso tal qual o mercador de Shakespeare: como um artifício para o descumprir. Não apenas porque as próprias ideologias ajudaram a o formatar, colocando nele seu fim, tampouco pelo fato de um respeito oco a essa geração fundante, mas pelo fato de que aquele é o instrumento que adstringe a voz de todas as razões em uma república das razões. Afinal, a pergunta epigrafada de Laurence Tribe e Michael Dorf, sobre se a Constituição é apenas um espelho em que cada um vê nela apenas o que quer ${ }^{54}$, merece uma resposta negativa.

Evidentemente, essa adstringência que liga fins plurais no norte de uma Constituição não é perfeita para todos e para cada um. Surge dela um problema central, o "dilema de Madison”, o qual consiste em conciliar dois princípios antagônicos: o autogoverno, referente ao direito dado às maiorias para governar,

49. Trata-se da chamada "social thesis", aceita como tese central entre as mais diversas concepções positivistas. Sobre o tema, vide, dentre outros: Coleman y LeIter (1999) p. 241-59.

50. A questão da diferença na formação do consenso é um ponto nodal da Teoria da Justiça de John Rawls (RAWLS, 1999), ponto no qual, aliás, sua teoria enfrentará talvez a sua maior crítica (vide, por todos: SANDEL, 1982).

51. NieTZSCHe [s/d].

52. Sunstein (1993), p. 8.

53. SunsteIn (1993), p. 347.

54. Tribe y Dorf (1991), p. 6. 
justificado pelo fato de ser uma maioria; e as restrições dos poderes da maioria contra as minorias ${ }^{55}$.

A solução só se faz possível, porém, desde que mantido o sistema jurídico criado pela Constituição, preservando sua estrutura, competência e autoridade. $\mathrm{Na}$ república das razões, tem o Tribunal Constitucional, por guardião da Constituição que é, uma verdadeira "representação argumentativa" 56 do cidadão para essa preservação. Disto, e não de uma despicienda, ainda que útil, regra (art. 93, IX da $\mathrm{CF} / 88$ ), surge o dever de fundamentar. Ele é mecanismo de controle, que só pode operar a partir da lógica normativa, ainda que uma lógica normativa dialética, plural e discursiva.

Eis o último passo para a resposta do primeiro problema formulado: a relação entre a Constituição e os dois tipos de ideologia no momento posterior à política constitucional.

Ultrapassada a política, em que as ideologias fortes e fracas de algum modo sublimam-se na Constituição, impera que as ideologias em sentido forte sejam extirpadas, eis que elas, expressa ou tacitamente, nos joguetes de poder que realizam na visada de interesses particulares implodem o interesse público, sem o qual as Constituições perdem sentido.

As ideologias fortes, portanto, ultrapassado o momento da política, estão em um lugar à margem da Constituição (são praeter constitucionais). As ideologias fracas, por outro lado, merecem constante atenção do direito, desde que, é claro,transportadas à gramática constitucional. A rigor, essa atenção não se lhes dará, portanto, enquanto ideologias, mas enquanto Constituição (são elas, pois, intra constitucionais).

O que se busca, ao fim e ao cabo dessas divisões, é a uma "ética da leitura" 57 cujo a priori, se há, é o a priori de um transcendental não clássico ${ }^{58}$. O a priori dos princípios formadores do núcleo mais rígido de uma Constituição: os seus direitos fundamentais ${ }^{59}$. Vale ressaltar: esse núcleo não se pode fazer trespassar

55. A exposição sobre o dilema de Madison e o seu enfrentamento é uma síntese de: Bork (1993).

56. Alexy (2007), p. 53.

57. Sobre uma "ética da leitura” no Direito, vide: PAsqualini (2002).

58. Cf. STEIN (2006).

59. Nesse sentido, após lembrar o art. 16 da Declaração Francesa dos Direitos do Homem e do Cidadão (1789), a qual prescrevia que "toda sociedade na qual a garantia dos direitos não é assegurada (...) não possui Constituição”, Ingo Sarlet assere: “Os direitos fundamentais integram, 
por qualquer ideologia, exceto quando essas ideologias sejam, elas mesmas, Constituição.

Não se põe a negar, com isso, que as ideologias desempenham um importante papel dentro e fora da Constituição, notadamente em dois âmbitos: o da interpretação constitucional e o das mutações constitucionais. Ao contrário, reconhece-se valia aos fatos de que: (a) o Tribunal Constitucional é um poder político ${ }^{60}$; (b) a Constituição incorpora uma concepção de Living Constitution que imprime novas leituras a textos antigos ${ }^{61}$; (c) o texto constitucional é uma "trama aberta" (open texture $)^{62}$; (d) a Constituição em si é aberta, tendo a sociedade também como intérprete ${ }^{63}$; e (e) o juiz, enquanto intérprete qualificado pelo ordenamento para dar as últimas respostas, conserva suas ideologias ${ }^{64}$ em uma biografia que afeta a subsunção ${ }^{65}$.

Sem negar essas verdades que foram paulatinamente, ao longo do último século, vigoradas no âmbito da Teoria do Direito e do Direito Constitucional, crê-se que é possível, agora e sempre, avalizar uma conclusão posta ainda sob uma baliza da hermenêutica clássica: “(...) a função do juiz, quanto aos textos, é dilatar, completar e compreender; porém não alterar, corrigir, substituir. (...) tudo procura achar e resolver com a lei; jamais com a intenção descoberta de agir por conta própria, praeter ou contra legem" ${ }^{66}$.

A propósito de ler os textos passados com os olhos do presente, cremos que o jurista aceitaria reescrever a frase substituindo "com a lei" por "com a Constituição". O mesmo não faria, especulamos, por "com o direito achado na rua" ${ }^{67}$.

portanto, ao lado da definição da forma de Estado, do sistema de governo e da organização do poder, a essência do Estado constitucional, constituindo, neste sentido, não apenas parte da Constituição formal, mas também elemento nuclear da Constituição material”. SARLET (2004), p. 68-69.

60. Cf. Souza Júnior (2002), p. 117.

61. TRIBE (2000), p. 79-80.

62 Guastini (2005), p.145.

63. Sobre os temas "Constituição aberta", "sociedade dos intérpretes" e "interpretação populista”, vide, respectivamente: BONAVIDES (1996); HÄBERLE (2002); TusHNET (2000).

64. Ricoeur (1977), passim; Guastini (2006), p. 217-56.

65. Haeberlin (2006), p. 169-188.

66. Maximiliano (2005), p. 65.

67. Lyra FiLho (1993), p. 55-60. 


\section{O mandamento da não egotopia e a desideologização da participação política}

Expôs-se a participação política como direito, conformada por princípios e regras. Também se expôs a teoria da ideologia, lembrando seu caráter de práxis, propondose um consectário da divisão entre ideologias fracas e fortes: afirmar que aquelas podem constar do texto constitucional (sendo, quando positivadas, intra constitucionais) e essas devem ser extirpadas dele (sendo, sempre, praeter constitucionais).

Nosso propósito, agora, passa a ser o de responder à segunda pergunta formulada: como o direito e a ideologia separam-se (ou devem ser separados)? Exerce-se aqui o móbil da proposta deste ensaio: desideologizar o direito de feição constitucional, o que significa, em outros termos, separar a participação política da egotopia que costuma a acompanhar.

O problema aqui enfrentando possui duas vias. De um lado, ele se dirige à necessidade de reconhecimento, por parte das maiorias, da diversidade como constituinte do Estado. Nesse ponto, ele é endereçado ao referido "dilema de Madison". De outro lado, o problema dirige-se à necessidade de reconhecimento, por parte das maiorias e minorias, de um senso de justiça como constituinte do Estado.

Este último ponto remete ao chamado "equilíbrio reflexivo" (reflective equilibrium $)^{68}$. Tal equilíbrio conduz à ideia de que, na consideração de suas pautas, indivíduos e grupos busquem uma postura menos auto-interessada e mais razoável. Leva-se em consideração o fato de que "[...] a estrutura básica e as suas políticas públicas devem ser justificadas a todos os cidadãos, como exige o princípio da legitimidade política" ${ }^{69}$.

Uma vez que a colisão de direitos fundamentais, verdadeira contingência das sociedades plurais no contexto de uma "trama aberta" dos princípios, permite diversas interpretações possíveis, tem-se aqui um problema de ordem moral. A malversação das interpretações normativas. Isso é: indivíduos e grupos, à parte da razoabilidade, subdimensionarem alguns princípios e relativizarem outros com o plano de fazer, da "trama aberta" constitucional, uma pauta de sentido único.

Eis, aqui, o comportamento que podemos designar como "egotopia". Egotopia refere-se a um "lugar" (topos) onde se quer encontrar apenas a "si", o “eu” (ego). Um “egotópos” seria, portanto, o "lugar que é meu”. Egotopia é a

68. Cf. RAWLS (1999), passim, mas especialmente p. 42-6.

69. RaWls (1996), p. 224. 
tentativa constante de alastrar o "lugar que é meu" para todos os espaços possiveis, públicos e privados, em um movimento que negligencia (dolosa ou culposamente) o espaço dos outros ${ }^{70}$. A expressão designa, portanto, um modo de ver a Constituição em que ela é espelho das próprias demandas (individuais ou coletivas), e onde a compatibilidade de sua leitura com o todo social é esquecido.

O problema da egotopia surge exatamente quando os princípios constitucionais -e os discursos relacionados a eles-deixam o plano jurídico e ganham morada nas ideologias.

No vínculo social, encontra-se a origem comum dos princípios e das ideologias. Porém, à luz do pressuposto de que os princípio se as regras seguem indefinidamente no sistema ao passo que as ideologias, após a Constituição, vivem dele à margem, entendemos possível realizar uma desideologização dos princípios constitucionais. Isso é possível apontando dessemelhanças entre princípios e ideologias resumidas em cinco características: i) quanto ao comportamento no sistema (os princípios são archai; as ideologias práxis); ii) quanto à forma de atuação (os princípios são normas jurídicas; as ideologias, orientações sociais); iii) quanto ao fim de atuação (os princípios estabelecem a busca de um estado de coisas e limites à ação do Estado, às omissões do Estado, às ações privadas; as ideologias estabelecem vínculos enraizados); iv) quanto à formação de consenso (os princípios formam-se do consenso e estabelecem, a partir dele, disposições; as ideologias buscam impor posições, independentemente do consenso); e v) quanto à lógica do discurso (os princípios realizam-se na ponderação; as ideologias trabalham com argumentos imponderáveis).

A desideologização é uma espécie de defesa do povo em relação à atuação estatal, vedando transformar a participação política em egotopia. E isso é absolutamente necessário, uma vez que, junto ao discurso das normas como princípios, testemunhamos, hodiernamente, uma espécie de "ideologia dos direitos humanos"71, isso é, uma produção egotópica dos direitos humanos e fundamentais. Trata-se da interpretação dos direitos humanos e fundamentais desde concepções excludentes, providas por grupos politicos ou sociais de matriz identificável, usualmente arraigados

70. Peter Koller, abrangendo esse sentido, fala em um "egoísmo de grupos” (Gruppenegoismus). Cf. Koller (2002), p. 53.

71. A utilização do termo "direitos humanos" é mais recorrente que a utilização do termo "direitos fundamentais", com o intuito, parece-nos, de conceder alguma vagueza ao que não tem, fugindo-se assim do direito em sua dimensão objetiva. 
às chamadas minorias" ${ }^{72}$. Esses grupos, defendendo "causas" (ideológicas) no lugar de argumentos(constitucionais), capitulam direitos a partir de um projeto de poder, com orientações e comportamentos padronizados, cujo objetivo prevalece, por imposição dogmática, sobre todo o sistema jurídico.

Nessas produções egotópicas, os direitos humanos e fundamentais viram um campo de batalha, onde a força dos argumentos é substituída pela força das convicções. Elas impõem à sociedade, como se lhe mostrando a vitrine das suas conquistas, o avesso do produto de suas conquistas. Flagra-se, nessa crítica, uma erística dos direitos fundamentais dissociada do conteúdo dos direitos fundamentais. Uma espécie de totalitarismo (tácito, impregnado e mordaz) que sequestra os princípios fundamentais da ordem constitucional e os torna reféns de propósitos que, ainda quando elevados, são, na verdade, espúrios do pressuposto democrático em que se funda a Constituição ${ }^{73}$.

O espaço da fundamentação -não como mera motivação, mas entendida no sentido da busca de razões consonantes a um entendimento-, é exatamente o campo em que a participação política ganha densidade e a partir da qual deve ser pensada. Daí evocarmos o conceito de "equilíbrio reflexivo", desenvolvido por Rawls, assim sintetizável:

Do ponto de vista da teria moral, a maior consideração do senso de justiça de uma pessoa não é aquela que se encaixa ao seu julgamento antes que ela examine qualquer concepção de justiça, mas aquela que combina os seus julgamentos em um equilíbrio reflexivo. Como vimos, esse estágio é alcançado depois de uma pessoa ter sopesado várias concepções propostas e, então, ela ou revisou o seu julgamento de acordo com alguma das concepções apresentadas, ou ela se manteve em suas convicções iniciais (e a sua correspondente concepção $)^{74}$.

72. O uso do termo "minoria”, atualmente, não guarda relação com a utilização do termo na Ciência Política clássica, referente a minorias numéricas em uma democracia. Ao se apor o termo "minoria" a determinados grupos, como se faz na atualidade, quer-se dizer que, historicamente, esses grupos estiveram mais afastados dos centros de poder. São, por isso, "historicamente sotopostos", isso é, "colocados por baixo" desses centros. Por essa razão, preferimos a utilização desse termo ao termo "minoria" nesses casos. Para um estudo sobre o porquê de alguns grupos terem ganho, historicamente, maior representação em suas causas (e, com isso, uma explicação da interessante temática do "lobby", ainda que mais serviente aos Estados Unidos), vide: Grossmann (2012).

73. Note-se, ainda e mais uma vez, que a crítica aqui referida e a própria concepção de democracia é válida “para além da esquerda e da direita”, para usar a expressão de: GIDDENs (1996).

74. RaWls (1999), p. 43. 
Poderíamos dizer, à vista do conceito, que a compreensão da participação política compatível com o interesse público (que se afastada egotopia) passa por três estágios.

O primeiro estágio é o da busca pelo equilíbrio reflexivo, onde se devem rechaçar os pensamentos em bloco e apriorísticos, isso é, aqueles cujo resultado já se conhece anteriormente à ponderação e à fundamentação a ela correspondente. $\mathrm{Na}$ busca pelo equilíbrio reflexivo, a pergunta que deve acossar os defensores dos direitos de comunidades específicas (como religiosos, ruralistas, negros, índios, mulheres, LGBTs, crianças, idosos, etc.), é: “como podemos inserir a nossa pauta na noção de bem comum da sociedade em geral?” e não aquela que recorrentemente aparece, que é "como podemos transformar a noção de bem comum da sociedade em geral em nossa pauta?”. A primeira pergunta faz com que a noção de bem comum ganhe densidade (e gere efetiva participação política). A segunda, com que seja estrangulada (e produza não mais do que egotopia).

O segundo estágio, não se conseguindo tomar um decisão de consenso para questões pontuais, após o equilíbrio reflexivo, compreende buscar meios para que as visões conflitantes sobre determinado objeto possam conviver em espaços distintos. Entender isso é entender que há espaços sociais de exclusão (desde que sejam privados), e que isso não adoece a ideia de justiça de uma sociedade. Ao contrário, a consagra em pluralismo. Isso porque diferentes comunidades ligam-se a diferentes valores. Por essa razão, parte do equilíbrio reflexivo é rejeitar a intrusão de valores em uma comunidade, desde que o objeto dessa comunidade não seja lesar os valores de outras. Toda introjeção impositiva de valores, de uma comunidade a outra, é uma espécie de violência moral. Busca-se, nesse estágio, uma postura de "não-pertencimento". Seria um exemplo de violência moral obrigar um padre da Igreja Católica a celebrar um casamento homoafetivo. Ora, isso não deve significar a rejeição da possibilidade do casamento igualitário. Cabe a esses nubentes, porém, entender que eles não pertencem, ao menos para essa questão, àquela comunidade, e, assim, respeitar os valores daquela comunidade. Tanto a introjeção de valores da Igreja ao casal, como do casal à Igreja, são espécies de violência moral, que não passam nesse segundo estágio de equilíbrio reflexivo.

O terceiro estágio é o da exceção. Isso é, quando não se obtém consenso em equilíbrio reflexivo em caso que determinada comunidade, em seu objeto ou forma de atuação, lesa valores e direitos de outra. Seria o exemplo de comunidades cristãs buscarem impedir o casamento homoafetivo não na sua Igreja, mas no espaço público. Nesse caso, a atuação estatal deve proteger os valores atingidos mesmo que deva agir por imposição vertical. 
A participação política ganha sua necessária "densidade" no tecido social operada nesses três estágios. Com eles, é possível propugnar um mandamento de não egotopia, assim constituído: "toda ação estatal deve fundamentar-se em equilíbrio reflexivo, evitando concepções obtusas dos direitos fundamentais capituladas por grupos com orientações e comportamentos padronizados, cujo objetivo prevalece, por imposição vertical, sobre todo o sistema jurídico, nele já incluídos os próprios direitos fundamentais"75.

A exposição desse litígio entre "participação política" e "egotopia", notese,acaba por desmantelar algumas posturas antidemocráticas. Dentre elas, as duas doutrinas de raiz totalizantes que impregnam a participação política: o comunismo e o liberalismo. Nenhuma delas, afinal, faz da participação política sua aliada.

\section{Conclusão}

O propósito do presente texto foi apresentar a participação política como um direito constitucional, o que importou em caracterizá-lo a partir de princípios e regras, diferenciando-a das ideologias. Essa diferenciação é sustentada no conteúdo normativo da participação política, em seu poder de obrigar constitucionalmente. Ideologias são orientações, não normas. E não-normas não normam.

A desideologização do direito, diz-se, é uma defesa do povo. De quê? Primeiro, dos modelos totalitários clássicos, que tem batido à porta de países latinoamericanos - conseguindo, por vezes, entrar. Segundo, de modelos totalitários contemporâneos. Sobre estes, devemos estar atentos ao fato de que os mecanismos de adaptação, singelos e sorrateiros que são nas ordens biológicas, o são também nas ordens sociais. Ainda quando se mostre diminuta, em razão das liberdades civis e das redemocratizações produzidas a partir do pós-guerra, a possibilidade de ressureição de autocracias que escrachem o sistema jurídico, não se pode descuidar da possibilidade de o antídoto da ordem democrática -os princípios formadores dos direitos fundamentais- transmudarem-se no seu próprio veneno.

Um dos caminhos, quiçá o único, de produção deum novo totalitarismo está no endosso de concepções dos direitos humanos e fundamentais que, negando seu conteúdo dentro do sistema jurídico-normativo, fazem com que estes sirvam às ideologias, notadamente quando, a pretexto de "curar" o Estado de suas doenças (os preconceitos econômicos, culturais, sociais, linguísticos até), servem a uma tirania

75. HaeberLin (2017), p. 291. 
de grupos associados a projetos de poder que impõem dogmática e verticalmente seus objetivos.

Surge, nesses casos, uma perigosa "ideologia dos direitos humanos" que impõe ao homem, como se lhe mostrando a vitrine de suas conquistas, o avesso do produto de suas conquistas. Impõe, como se fosse parte do discurso dos direitos humanos, a dissecação do elemento mais material e rígido constante em uma Constituição, que são esses direitos.As ideologias, como regra, são amigas do alternativo "direito achado na rua" na mesma proporcional medida em que são inimigas do direito achado na Constituição.

Vale a lembrança de um verso enigmático de Hölderlin, citado por Martin Heidegger em sua investigação sobre a técnica: "Aí, onde cresce o perigo, cresce também o que salva"76. Quiçá esses versos, considerando o problema aqui analisado, mereçam uma inversão, para dizer: Ai, onde cresce o que salva, cresce também o perigo.

Fomos salvos do abismo pelos direitos fundamentais. Mora neles, porém, mais precisamente em uma concepção obtusa deles, o perigo de comprar, em venda casada, uma ideologia que é passada adiante como sendo o seu subproduto.

Seguramente, haverá quem, em crítica, diga que a desideologização da participação política aqui defendida é nada mais que uma busca de propagar uma ideologia no lugar de outra ${ }^{77}$. Essa crítica padecerá de grave equívoco: não se está a tocar um réquiem de uma ideologia ou das ideologias, tampouco levantando a bandeira de qualquer outra. Está-se apenas as proclamando existentes e, com isso, as colocando em seu devido lugar, que é a política constitucional para, ato contínuo, as afastar da interpretação constitucional, espaço onde elas são visitantes inóspitas. O que se quer dizer, enfim, é que as ideologias devem entrar pela "escada da frente" da Constituição, não sorrateiramente, pela "escada dos fundos"78, onde o intangível controle das decisões judiciais pela fundamentação, o dono da casa em nossa metáfora, não se as permite notar.

Resta dizer que a participação política, enquanto direito conformado por normas jurídicas que encalçam a lógica discursiva dos direitos fundamentais na Constituição dos Estados Democráticos contemporâneos, é construto fundante e

76. Hölderlin apud HeIdegGer (1962).

77. Nesse sentido, propugnava Paulo Freire: "Na verdade, só ideologicamente posso matar as ideologias, mas é possível que não perceba a natureza ideológica do discurso que fala de sua morte.” Freire (2002), p. 149.

78. WEISCHEDEL (s/d). 
cogente desses Estados. Essa cogência só existe em uma abordagem constitucional que se afaste da egotopia ínsita às concepções ideológicas.

Eis um tema delicado, para o qual o turbilhão de acontecimentos políticos ocorridos recentemente na América Latina aponta vigília inexpugnável ao jurista que diligencie despregar os seus grilhões e se aperceber contra a alienação.

\section{Referências Bibliográficas}

AleXy, Robert (1994): Theorie der Grundrechte. 2a ed. (Frankfurt: Suhrkamp).

AlEXY, Robert (2007): "Direitos fundamentais no estado constitucional democrático: para a relação entre direitos do homem, direitos fundamentais, democracia e jurisdição constitucional". EnAlexy, Robert. Constitucionalismo discursivo (Traducción de HECK, Luís Afonso) (Porto Alegre, Livraria do Advogado).

ArendT, Hannah (1962): The Origins of Totalitarism. $2^{\mathrm{a}}$ ed. (Cleveland: The World Publishing Company). Disponible en: <https://archive.org/stream/ originsoftotalit00aren\#pa ge/n7/mode/2up $>$ [Fecha de consulta: 27 agosto de 2014].

Arnoud, André-Jean et al. (1999):Dicionário Enciclopédico de Teoria e de Sociologia do Direito. $2^{a}$ ed. (Traducción de BarRetTo, Vicente) (Rio de Janeiro, Renovar).

Aronne, Ricardo (2006): Direito Civil-Constitucional e Teoria do Caos. Estudos Preliminares (Porto Alegre, Livraria do Advogado).

Ávila, Humberto (2005): Teoria dos Princípios: da definição à aplicação dos princípios jurídicos. $4^{a}$ ed. (São Paulo, Malheiros).

Bonavides, Paulo (1996): Constituição Aberta: temas políticos e constitucionais da atualidade, com ênfase no federalismo das regiões. $2^{a}$ ed. (São Paulo, Malheiros).

Bonavides, Paulo (2004): Curso de Direito Constitucional. 14ª ed. (São Paulo, Malheiros).

BORK, Robert (1993): “The original understanding”. En BRISON, Susan; SinNoTArmstrong, Walter (org):Contemporary Perspectives on Constitutional Interpretation. (Boulder, Westview Press).

Canaris, Claus-Wilhelm (1989): Pensamento Sistemático e Conceito de Sistema na Ciência do Direito (Traducción deMenezes Cordeiro, Antonio) (Lisboa, Fundação Calouste Gulbenkian).

CANDÉ, Roland de (2001): História Universal da Música(Traducción de BRANDÃo,Eduardo; 
Revisión de ApPenzeller, Marina) (São Paulo, Martins Fontes).

CHAứ, Marilena (1984): O que é ideologia. (São Paulo, Abril Cultural/Brasiliense). Coelho, Luiz Fernando (2002): Teoria Crítica do Direito. $3^{\text {a }}$ ed. (Curitiba, Del Rey).

Coleman, Jules; Leiter, Brian (1999): “Legal Positivism”. En: Patterson, Dennis (ed.): A Companion to Philosophy of Law and Legal Theory. (Oxford, Blackwell).

Colin, Sumner (1979): Reading ideologies: an investigation into the Marxist theory of ideology and law. (London/New York: Academic Press).

Dworkin, Ronald (1999). Taking Rights Seriously. $7^{\text {a }}$ ed. (Cambridge, Harvard University Press).

EngeLs, Friedrich (s.d). Ludwig Feuerbach und der Ausgang der deutschen Philosophie. Disponible em: <http://www.mlwerke.de/me/me03/me03_533.htm>. [Fecha de consulta: 26 junio de 2017]

Finelli, R. (2001): “Marx e Gramsci: o confronto de duas antropologias". En Petrônio, G., Musitelli, M. P. (orgs.): Marx e Gramsci: memória e attualità. (Roma, Manifestolibri).

Freire, Paulo (2002): Pedagogia da Autonomia: saberes necessários à prática educativa. 24a edição (São Paulo, Paz e Terra).

FreITAS, Juarez (2004): A Interpretação Sistemática do Direito. $4^{a}$ ed. (São Paulo, Malheiros).

FukuYAma, Francis (1992): O fim da história e o último homem. (Traducción deRodrigues, Auly Soares) (Rio de Janeiro, Rocco).

Giddens, Anthony (1996): Para além da esquerda e da direita: o futuro da política radical. (Traducción de HatTnher, Alvaro) (São Paulo, UNESP).

Gramsci, Antonio (1975): Quaderni del cárcere. (Torino, Einaudi, Vol. 4).

Grimm, Dieter (1991): Die Zukunft der Verfassung. (Frankfurt am Main, Suhrkamp).

Grossmann, Matt (2012): The Not-So-Special Interests: Interest Groups, Public Representation, and American Governance (Stanford, Stanford University Press).

Guastini, Riccardo (2005): Das Fontes às Normas. (Traducción de BINI, Edson) (São Paulo, Quartier Latin).

GuASTINI, Riccardo (2006): “Teoria e Ideologia da Interpretação Constitucional”(Traducción de Leites, Henrique Moreira). En Interesse Público (Porto Alegre, ano 8, n. 40, nov./dez).

Häberle, Peter (2002): Hermenêutica Constitucional. A sociedade aberta dos intérpretes da Constituição: contribuição para a interpretação pluralista e 
"procedimental” da Constituição (Traducción de MENDEs, Gilmar Ferreira) (Porto Alegre, Sergio Fabris).

Haeberlin, Mártin (2006). "O Juiz e a Outra História: uma abordagem do princípio da imparcialidade a partir dos problemas da subsunção."En Revista da AJURIS (Porto Alegre, ano XXXIII, n. 104, dez. 2006).

Haeberlin, Mártin (2017): Uma Teoria do Interesse Público: fundamentos do Estado Meritocrático de Direito. (Porto Alegre, Livraria do Advogado).

Halpin, Andrew (2006). "Ideology and Law". EnJournal of Political Ideologies(Vol. 11, issue 2, p. 15-158). Disponibleem: <http://www.tandfonline.com/doi/abs/ 10.1080/13569310600687932 ?journalCode $=$ cjpi20 >. [Fecha de consulta: 27 junio de 2017]

Heidegger, Martin (1951): El Ser y El Tiempo. (Traducción de Gaos, José) (Buenos Aires, Fondo de Cultura Económica).

Heidegger, Martin (1962). "Die Frage nach der Technik". En: Die Technik und die Kehre (Stuttgart, Klett-Cotta).

Hoover, Jeffrey; Robinson, Scott (2007): "Retaliatory mafia behavior by a parasitic cowbird favors host acceptance of parasitic eggs."En: PNAS - Proceedings of the National Academy of Science of the United States of América (Vol. 104, n. 11, p. 4479-4483, March). Disponible em: <http://www.pnas.org/ content/104/11/4479.full.pdf>. [Fecha de consulta: 27 junio de 2017]

HunT, Alan (1985). "The Ideology of Law: advences and problems in recente applications of the concept of ideology to the analysis of law". En: Law and Society Review (Vol. 11). Disponible em: <http://heinonline.org/HOL/LandingPage? collection=journals\&handle=hein.journals $/$ lwsocrw19\&div=7\&id=\&page $>$. [Fecha de consulta: 27 junio de 2017].

IsENSEE, Josef (1995):Das Volk als Grund der Verfassung: Mythos und Relevanz der Lehre von der verfassungsgebenden Gewalt (Berlin, Springer).

JHERING, Rudolf von (1992): Der Kampf um's Recht (Frankfurt am Main, Propyläen).

JHERING, Rudolph von (1877): Der Zweck im Recht. (Vol. I, Leipzig, Breitkopf und Härtel). Disponible en: <https://archive.org/stream/derzweckimrecht04jhergoog\#page/ n11/mode/ 2up >. [Fecha de consulta: 12 agosto de 2017]

Koller, Peter (2002). "Das Konzept des Gemeinwohls: Versuch einer Begriff sexplication.”En: BRUGGER, Winfried; Kirste, Stephan; ANDERHEIDEN, Michael (org.): Gemeinwohl in Deutschland, Europa und der Welt. Interdisziplinäre Studien zu Recht und Staat (N. 24, Baden-Baden, Nomos).

Lumia, Giuseppe (2003): Elementos de Teoria e Ideologia do Direito (Traducción de Augustinetti, Denise) (São Paulo, Martins Fontes).

LyRA FiLHO, Roberto (1993): “Normas Jurídicas e outras normas sociais.”En: SOUSA 
JR., José Geraldo de (org.):O direito achado na rua: introdução crítica ao Direito. $4^{a}$ ed. (Brasília, Editora da Universidade de Brasília).

Mannheim, Karl (1976): Ideologia e Utopia. $3^{a}$ ed. (Rio de Janeiro, Zahar).

Marx, Karl; Engels, Friedrich (2002): A ideologia alemã.(Traducciónde Castro e Costa, Luis Cláudio de) (São Paulo, Martin Claret).

Marx, Karl; Engels, Friedrich (2002). Manifesto do Partido Comunista. (Traducción de Cassal, Sueli Tomazini Barros) (Porto Alegre, L \& PM).

Maximiliano, Carlos (2005): Hermenêutica e Aplicação do Direito. $19^{a}$ ed. (Rio de Janeiro, Forense).

Meira Penna, José Osvaldo de (1994): A Ideologia do Século XX: ensaios sobre o Nacional-socialismo, o Marxismo, o Terceiro-mundismo e a Ideologia Brasileira. $2^{\text {a }}$ ed. (Rio de Janeiro, Nórdica).

Montaigne, Michel de (1565): Les Essays. Livro III. Disponibleen: <http://www. cfh.ufsc.br/ conte/montaigne-essais-III.pdf $>$. \{Fecha de consulta: 09 de septiembre de 2017]

Nietzsche, Friedrich [s/d]. Vontade de Potência. (Traducción de SANTOS, Mário Ferreira) (Rio de Janeiro, Ediou).

PASQUALINI, Alexandre (2002): "Hermenêutica: uma crença intersubjetiva na busca da melhor leitura possível.”En: BOUCAULT, Carlos Eduardo de Abreu; Rodriguez, José Rodrigo (orgs.):Hermenêutica Plural. (São Paulo, Martins Fontes).

Pontes de Miranda, Francisco Cavalcanti (1972): Sistema de Ciência Positiva do Direito. $2^{\circ}$ ed. Tomo IV - Investigação Científica e Intervenção na Matéria Social. (Rio de Janeiro, Borsoi).

POPPER, Karl (1987): A sociedade aberta e seus inimigos. $3^{\text {a }}$ ed. (Belo Horizonte, Itatiaia).

Portanova, Rui (2003): Motivações ideológicas das sentenças. $5^{\mathrm{a}}$ ed. (Porto Alegre, Livraria do Advogado).

Puente, Fernando Rey (2003): “Télos como Archée o Fundamento Temporal da Ação em Aristóteles” En: Revista Philosophica ( ${ }^{\circ}$ 26, Instituto de Filosofía Pontifícia, Universidad Católica de Valparaíso).

Rawls, John (1996). Political Liberalism. (New York, Columbia University Press).

Rawls, John (1999). A Theory of Justice. (Oxford, Oxford University Press).

Ricoeur, Paul (1977): Interpretação e Ideologias. (Traducción de JAPIASSu, Hilton) (Rio de Janeiro, Francisco Alves).

SANDEL, Michael (1982): Liberalism and the Limits of Justice (Cambridge, Cambridge University Press). 
SARLET, Ingo Wolfgang (2004): A Eficácia dos Direitos Fundamentais. $4^{a}$ ed. (Porto Alegre, Livraria do Advogado).

SEverino, Antonio Joaquim (1986):Educação, Ideologia e Contra-ideologia. (São Paulo, EPU).

Souza JúnIor, Cezar Saldanha (2002): O Tribunal Constitucional como Poder: uma nova teoria da divisão dos poderes. (São Paulo, Memória Jurídica).

Stein, Ernildo (2006):Prefácio. En: Streck, Lenio Luiz: Verdade e consenso: constituição, hermenêutica e teorias discursivas. (Rio de Janeiro, Lumen Juris).

Sunstein, Cass (1993): The Partial Constitution. (Harvard: Harvard University Press).

TRIBE, Laurence; Dorf, Michael (1991): On reading the Constitution. (Cambridge, Harvard University Press).

TRIBE, Laurence (2000): American Constitutional Law. $3^{\mathrm{a}}$ ed. (New York, Foundation).

TusHnEt, Mark (2000): Taking the Constitution Away from the Courts. (Princeton, Princeton University Press).

VerheiJ, B.; Hage, J.C.; Van Den Herik, H.J (1998): “An Integrated View on Rules and Principles". En: Artificial Intelligence and Law (Vol. 6, No 1, Springer, p. 3-26).

WeisChedel, Wilhelm (s/d): Die philosophische Hintertreppe: 34 große Philosophen in Alltag und Denken. Disponible em: <http:/www.wehavephotoshop.com/ PHILOSOPHY\% 20NOW/PHILOSOPHY/Nachschlagewerke/Weischedel\%20 -\%20Die\%20philosophische\%20Hintertreppe.pdf>. [Fecha de consulta: 09 de septiembre de 2017]

Wolkmer, Antonio Carlos (2000): Ideologia, Estado e Direito. $3^{\text {a }}$ ed. (São Paulo, Revista dos Tribunais).

Zanobi, Guido (1950): Corso di Diritto Amnistrativo. Vol. 1 - Principî Generali. $6^{a}$ ed. (Milano, Giuffrè). 